\title{
WARUNKI TECHNICZNE W ODNIESIENIU DO TERMOMODERNIZACJI OBIEKTÓW ZABYTKOWYCH
}

\author{
Wojciech Rogala ${ }^{凶}$ \\ Wydział Inżynierii Lądowej, Politechnika Warszawska, Warszawa
}

\begin{abstract}
STRESZCZENIE
Przedmiotem pracy jest zagadnienie ekonomicznej opłacalności termomodernizacji obiektów zabytkowych w świetle aktualnych przepisów w zakresie ochrony cieplnej budynków. Analizie poddano dwie kondygnacje budynku wielorodzinnego, adaptowanego na cele biurowe. W obliczeniach uwzględniono trzy technologie ocieplenia od wewnątrz - wełnę mineralną na ruszcie drewnianym, mineralne płyty izolacyjne oraz płyty poliuretanowe z warstwą g-k. Dobrane warianty spełniają wymagania w zakresie granicznych wartości współczynnika przenikania ciepła (U), określone w stosownych przepisach na lata 2013, 2014, 2017 oraz 2021. Do analizy wykorzystano metodę NPV, uzupełnioną o koszt utraty powierzchni użytkowej. Analiza w okresie piętnastoletnim wskazuje nierentowność przedsięwzięcia termomodernizacji od wewnątrz po zaostrzeniu przepisów dotyczących ochrony cieplnej budynków w 2014, 2017 oraz 2021 roku.
\end{abstract}

Słowa kluczowe: ocieplenie od wewnątrz, termomodernizacja obiektów zabytkowych, wymogi dla budynków zabytkowych, charakterystyka energetyczna budynków zabytkowych

\section{WSTĘP}

Pierwszego stycznia 2014 roku weszło w życie Rozporządzenie Ministra Transportu, Budownictwa i Gospodarki Morskiej z dnia 5 lipca 2013 r. zmieniające rozporządzenie w sprawie warunków technicznych, jakim powinny odpowiadać budynki i ich usytuowanie (Dz.U. 2013 poz. 926). Wraz z nowelizacją został zmodyfikowany zapis $\S 329$ pkt 1 us. 1, umożliwiający zredukowanie granicznych wartości współczynnika przenikania ciepła dla przegród w budynkach przebudowywanych. Zgodnie z rozporządzeniem z dnia 5 lipca 2013 roku, graniczne wartości współczynników przewodzenia ciepła będą sukcesywnie zaostrzane do 1 stycznia 2021 roku.

Niezależnie od regionu obiekty z elewacjami o wartości historycznej charakteryzują się znacznymi walorami lokalizacyjnymi. Stają się przez to atrakcyjne do przebudowy i adaptacji, m.in. na cele biurowe lub hotelowe. Ograniczona dostępność nieodnawialnych źródeł energii oraz ograniczona dostępność materiałów izolacyjnych w czasie ich budowy spowodowały, że charakterystyka energetyczna takich obiektów nie spełnia współczesnych wymagan. Ponadto wobec wysokich cen nośników energii koszty eksploatacji tych obiektów są obecnie znaczne. Dlatego ich koszty przebudowy nie uwzględniają jedynie prac związanych z dostosowaniem do innego przeznaczenia, ale także konieczność termomodernizacji.

Zgodnie z art. 5 pkt 2 b Ustawy z dnia 7 lipca 1994 - Prawo budowlane (Dz.U. 2016 poz. 290), jeśli roboty polegające na dociepleniu budynku obejmują ponad $25 \%$ powierzchni przegród zewnętrznych, to konieczne jest spełnienie minimalnych wymagań dotyczących energooszczędności i ochrony cieplnej. Oznacza to, że

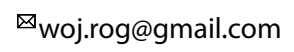


spełnienie granicznych wartości współczynnika przewodzenia ciepła $(U)$ wymagane jest również dla obiektów zabytkowych.

Ocieplenie od wewnątrz nie jest zalecanym sposobem izolacji przynajmniej z kilku powodów (Harassek i Bajno, 2016):

- zły dobór systemu może spowodować narastającą ilość kondensatu pary wodnej wewnątrz przegrody,

- straty ciepła przez mostki termiczne są znacznie większe niż przy ociepleniu od strony zewnętrznej,

- zmniejsza się zdolność akumulacji energii cieplnej w przegrodach zewnętrznych,

- izolacja od strony wewnętrznej zmniejsza powierzchnię użytkową,

- systemy izolacji od wewnątrz są znacznie droższe od systemów ETICS.

Z uwagi na często występującą dużą wartość historyczną lub architektoniczną elewacji, pomimo wielu wad, ocieplenie od wewnątrz jest zazwyczaj jedynym sposobem na ograniczenie strat energii przez ściany zewnętrze. Ostatnie lata spowodowały znaczny wzrost dostępnych technologii izolacji od wewnątrz, które z uwagi na przepływ pary wodnej w okresie jesienno-zimowym odróżniają się od technologii ocieplania od zewnątrz. Można je podzielić na trzy grupy:

1. Tradycyjna metoda ocieplenia wełną mineralną na ruszcie drewnianym z poszyciem płytą g-k. Technologia wymaga zastosowania folii paroszczelnej od strony wewnętrznej.

2. Materiały otwarte na dyfuzję pary wodnej (np. płyty z lekkiego betonu komórkowego, płyty krzemianowe), które gromadzą wilgoć w okresie jesienno-zimowym i oddają do wnętrza w okresie letnim. Warunkiem poprawnego funkcjonowania izolacji jest wykonanie analizy cieplno-wilgotnościowej i określenie, czy dana konstrukcja przegrody jest w stanie zgromadzić wytwarzającą się ilość kondensatu.

3. Materiały o wysokim współczynniku oporu dyfuzyjnego (np. płyty poliuretanowe z doklejoną warstwą g-k), które stanowią barierę dla pary wodnej. Izolacja może działać poprawnie, pod warunkiem szczelnych połączeń pomiędzy płytami.

Wymagane wartości współczynnika przenikania ciepła $\left(U\left[\mathrm{~W} \cdot \mathrm{m}^{-2} \cdot \mathrm{K}^{-1}\right]\right)$ zaprezentowano w tabeli 1 . Wraz z początkiem 2017 roku nastapił drugi etap zaostrzania przepisów dotyczących granicznego zużycia energii cieplnej (Dz.U. 2013 poz. 926). W porównaniu z przepisami obowiązującymi do 31.12.2013 roku konieczna grubość izolacji od wewnątrz wzrosła średnio o $6 \mathrm{~cm}$ (tab. 2). Pozornie niewielka zmiana w praktyce jest istotna $\mathrm{z}$ trzech powodów. Średnia cena tzw. otwartych na dyfuzję materiałów do izolacji od wewnątrz jest około pięciokrotnie wyższa od ceny materiałów do ocieplania od zewnątrz. Dodatkowo izolacja od strony wewnętrznej wpływa na zmniejszenie powierzchni użytkowej budynku, dlatego przy chęci późniejszej odsprzedaży lub najmu wpływa

Tabela 1. Wymagane wartości współczynników przenikania ciepła dla przegród zewnętrznych (Dz.U. 2013 poz. 926)

Table 1. Required values of heat transfer coefficient for external partitions (Dz.U. 2013 poz. 926)

\begin{tabular}{lcccc}
\hline $\begin{array}{l}\text { Rodzaj budynku } \\
\text { Kind of building }\end{array}$ & $\begin{array}{c}\text { WT 2013 } \\
(\text { do } / \text { till 31.12.2013) }\end{array}$ & $\begin{array}{c}\text { WT 2014 } \\
\text { (od / from 1.01.2014) }\end{array}$ & $\begin{array}{c}\text { WT 2017 } \\
\text { (od / from 1.01.2017) }\end{array}$ & $\begin{array}{c}\text { WT 2021 } \\
\text { (od / from 1.01.2021) }\end{array}$ \\
\hline $\begin{array}{l}\text { Budynki nowo } \\
\text { wznoszone }\end{array}$ & $U \leq 0,30 \mathrm{~W} \cdot \mathrm{m}^{-2} \cdot \mathrm{K}^{-1}$ & & & \\
New buildings & & $U \leq 0,25 \mathrm{~W} \cdot \mathrm{m}^{-2} \cdot \mathrm{K}^{-1}$ & $U \leq 0,23 \mathrm{~W} \cdot \mathrm{m}^{-2} \cdot \mathrm{K}^{-1}$ & $U \leq 0,20 \mathrm{~W} \cdot \mathrm{m}^{-2} \cdot \mathrm{K}^{-1}$ \\
$\begin{array}{l}\text { Budynki } \\
\text { modernizowane }\end{array}$ & $U \leq 0,345 \mathrm{~W} \cdot \mathrm{m}^{-2} \cdot \mathrm{K}^{-1}$ & & & \\
Redecorated buildings & & &
\end{tabular}

Objaśnienie: WT - wymogi według Rozporządzenia (Dz.U. 2013 poz. 926) wraz z rokiem obowiązywania.

Explanation: WT - requirements form Regulation (Dz.U. 2013 poz. 926) with year of validity. 
Tabela 2. Wymagana grubość izolacji [cm] przy ociepleniu od wewnątrz (opracowanie własne)

Table 2. Required thickness of insulation [cm] for partitons insulated from internal side (own work)

\begin{tabular}{|c|c|c|c|c|c|c|c|c|c|c|c|c|c|c|c|c|c|c|c|c|}
\hline \multirow{2}{*}{$\begin{array}{l}\text { Parametry izolacji } \\
\text { Insulation parameters } \\
\text { Grubość muru [cm] } \\
\text { Masonry thickness [cm] }\end{array}$} & \multicolumn{5}{|c|}{ WT 2013} & \multicolumn{5}{|c|}{ WT 2014} & \multicolumn{5}{|c|}{ WT 2017} & \multicolumn{5}{|c|}{ WT 2021} \\
\hline & 25 & 38 & 51 & 64 & 77 & 25 & 38 & 51 & 64 & 77 & 25 & 38 & 51 & 64 & 77 & 25 & 38 & 51 & 64 & 77 \\
\hline $\begin{array}{l}\text { Mineralne płyty } \\
\text { izolacyjne } \\
\text { Mineral insulation boards }\end{array}$ & 11 & 10 & 9 & 9 & 8 & 15 & 15 & 14 & 13 & 13 & 17 & 16 & 16 & 15 & 14 & 20 & 19 & 18 & 18 & 17 \\
\hline $\begin{array}{l}\text { Wełna mineralna } \\
\text { na ruszcie drewnianym } \\
\text { Mineral wool on wooden } \\
\text { frame }\end{array}$ & 11 & 10 & 9 & 8 & 8 & 16 & 15 & 14 & 13 & 13 & 18 & 17 & 16 & 15 & 14 & 21 & 20 & 19 & 18 & 17 \\
\hline $\begin{array}{l}\text { Płyty poliuretanowe } \\
\text { z warstwą g-k } \\
\text { Polyurethane board } \\
\text { with plasterboard }\end{array}$ & 7 & 6 & 6 & 6 & 5 & 9 & 9 & 8 & 8 & 8 & 10 & 9 & 9 & 9 & 8 & 11 & 11 & 10 & 10 & 10 \\
\hline
\end{tabular}

Objaśnienia: Przyjęty mur z cegły pełnej $\left(\lambda=0,77 \mathrm{~W} \cdot \mathrm{m}^{-1} \cdot \mathrm{K}^{-1}\right)$ otynkowany od wewnątrz tynkiem cem-wap. $1,5 \mathrm{~cm}$; WT - wymogi według Rozporządzenia (Dz.U. 2013 poz. 926) wraz z rokiem obowiązywania.

Explanations: Calculation for solid brick wall $\left(\lambda=0.77 \mathrm{~W} \cdot \mathrm{m}^{-1} \cdot \mathrm{K}^{-1}\right)$ plastered from inside with cement-lime plaster $1.5 \mathrm{~cm}$ thick; WT - requirements form Regulation (Dz.U. 2013 poz. 926) with year of validity.

negatywnie na rentowność przedsięwzięcia termomodernizacyjnego. Większa grubość izolacji od wewnętrznej strony wpływa także negatywnie na ilość kondensatu gromadzonego wewnątrz przegrody w okresie jesienno-zimowym i utrudnia zadanie termomodernizacji.

Celem pracy jest zweryfikowanie, jak kolejne etapy zaostrzania wymogów dotyczących granicznych wartości współczynnika przenikania ciepła $(U)$ wpływają na rentowność przedsięwzięcia termomodernizacyjnego.

\section{MATERIAt I METODY}

Analizie poddano budynek z cegły pełnej, zlokalizowany w Warszawie, przeznaczony do adaptacji na cele biurowe. Grubość ścian zewnętrznych w budynkach historycznych wynosi najczęściej od $25 \mathrm{~cm}$ (gr. 1c) do $77 \mathrm{~cm}$ (gr. 3c). Grubość muru zwykle zmniejsza się na kolejnych kondygnacjach. Dlatego analizę przeprowadzono dla dwóch grubości - 1,5c $(38 \mathrm{~cm})$ oraz $3 \mathrm{c}(77 \mathrm{~cm})$. W obliczeniach uwzględniono jedną kondygnację naziemną budynku o łącznej powierzchni przegród zewnętrznych, wynoszącej 145,6 $\mathrm{m}^{2}$ (w tym 23,4 $\mathrm{m}^{2}$ okien) oraz powierzchni użytkowej $-133,2 \mathrm{~m}^{2}$. Do analizy przyjęto jedynie straty ciepła przez przegrody zewnętrzne pionowe i wentylację, bez uwzględniania mostków termicznych. Przyjęto koszt wytworzenia energii cieplnej $0,28 \mathrm{z} \cdot \mathrm{kWh}^{-1}$. Rozważono trzy technologie wykonania izolacji: mineralne płyty $\mathrm{z}$ betonu komórkowego $\left(\lambda=0,043 \mathrm{~W} \cdot \mathrm{m}^{-1} \cdot \mathrm{K}^{-1}\right)$, płyty poliuretanowe $\mathrm{z}$ doklejoną warstwą $\mathrm{g}-\mathrm{k}\left(\lambda=0,022 \mathrm{~W} \cdot \mathrm{m}^{-1} \cdot \mathrm{K}^{-1}\right)$ oraz wełnę mineralną na ruszcie drewnianym $\left(\lambda=0,037 \mathrm{~W} \cdot \mathrm{m}^{-1} \cdot \mathrm{K}^{-1}\right)$ pokrytą folią paroszczelną i płytą $\mathrm{g}-\mathrm{k}$.

Każdy z wariantów technologicznych przeanalizowano dla grubości izolacji (dostępnych w ofercie producentów), które są konieczne do spełnienia minimalnych wartości współczynnika przenikania ciepła $(U)$ w latach 2013-2021 (Dz.U. 2008 nr 201 poz. 1238 oraz Dz.U. 2013 poz. 926). W obliczeniach dodatkowo uwzględniono wariant minimalny, który zgodnie z pkt 2.2.2 załącznika nr 2 (Dz.U. $2008 \mathrm{nr} 201$ poz. 1238) ogranicza ryzyko rozwoju grzybów pleśniowych, które z kolei są przyczyną chorób skóry, alergii i infekcji układu oddechowego 
(Ostańska i Barnat-Hunek, 2014). Obliczenia wykonano za pomocą aplikacji BuildDesk Energy Certificate Proffessional na podstawie norm: PN-EN ISO 6946:1999, PN-EN ISO 6946:2008, PN-EN ISO 13790:2009 oraz PN-EN ISO 13789:2008. Koszt wykonania izolacji oszacowano na podstawie średnich cen ofertowych.

Analizę opłacalności wykonano według metody NPV. Przyjęto stopę dyskonta $1,5 \%$ oraz szacowany realistyczny wzrost cen energii 3,8\% rocznie na podstawie Prognozy wzrostu cen energii elektrycznej i ciepła dla gospodarstw domowych i przedsiębiorstw w województwie mazowieckim (Bioenergia dla regionu - Badanie zarządzania zmianą gospodarcza, 2012). Uwzględniono piętnastoletni czas trwania inwestycji. W analizie uwzględniającej utraconą powierzchnię użytkową przyjęto średni wzrost kosztów najmu nieruchomości 1\% rocznie.

\section{WYNIKI}

Obliczenia zawarte w tabeli 3 wskazują na spadek kosztów ogrzewania, w zależności od wybranego wariantu, o 53-58\% w przypadku wariantu eliminującego ryzyko kondensacji powierzchniowej, który przekłada się na minimalną grubość izolacji dostępną w ofercie producentów. Mniej istotny, ale dalej znaczący spadek można zaobserwować przy wariancie WT 2013.

Tabela 3. Analiza rocznych kosztów energii cieplnej do celów grzewczych i wentylacji oraz kosztów wykonania izolacji (opracowanie własne)

Table 3. Analysis of heat + ventilation annual costs and costs of insulation installation, depending on legal requirements (own work)

\begin{tabular}{|c|c|c|c|c|c|c|c|}
\hline $\begin{array}{l}\text { Materiał izolacyjny } \\
\text { Insulation material }\end{array}$ & $\begin{array}{c}\text { Grubość } \\
\text { muru } \\
{[\mathrm{cm}]} \\
\text { Masonry } \\
\text { thickness } \\
{[\mathrm{cm}]}\end{array}$ & $\begin{array}{c}\text { Koszty }[\mathrm{PLN}] \\
\text { Costs }[\mathrm{PLN}]\end{array}$ & $\begin{array}{l}\text { Wariant } \\
\text { minimalny } \\
\text { Basic } \\
\text { insulation }\end{array}$ & WT 2013 & WT 2014 & WT 2017 & WT 2021 \\
\hline \multirow{2}{*}{$\begin{array}{l}\text { Budynek } \\
\text { nieocieplony } \\
\text { Building without } \\
\text { insulation }\end{array}$} & 38 & \multirow[b]{2}{*}{ koszt ogrzewania - heating cost } & & & 7621 & & \\
\hline & 77 & & & & 4595 & & \\
\hline \multirow{4}{*}{$\begin{array}{l}\text { Mineralne płyty } \\
\text { izolacyjne } \\
\text { Mineral insulation } \\
\text { boards }\end{array}$} & \multirow{2}{*}{38} & koszt ogrzewania - heating cost & 3271 & 2421 & 2023 & 2023 & 1879 \\
\hline & & koszt izolacji - insulation cost & 17538 & 24527 & 32914 & 32914 & 38505 \\
\hline & \multirow{2}{*}{77} & koszt ogrzewania - heating cost & 4595 & 2403 & 2015 & 2015 & 1874 \\
\hline & & koszt izolacji - insulation cost & 0 & 21731 & 30118 & 30118 & 35710 \\
\hline \multirow{4}{*}{$\begin{array}{l}\text { Wełna mineralna } \\
\text { na ruszcie } \\
\text { drewnianym } \\
\text { Mineral wool on } \\
\text { wooden frame }\end{array}$} & \multirow{2}{*}{38} & koszt ogrzewania - heating cost & 3234 & 2430 & 2088 & 1964 & 1900 \\
\hline & & koszt izolacji - insulation cost & 9801 & 10993 & 12188 & 12904 & 13382 \\
\hline & \multirow{2}{*}{77} & koszt ogrzewania - heating cost & 4595 & 2394 & 1982 & 1982 & 1885 \\
\hline & & koszt izolacji - insulation cost & 0 & 10516 & 12188 & 12188 & 12904 \\
\hline \multirow{4}{*}{$\begin{array}{l}\text { Płyty } \\
\text { poliuretanowe } \\
\text { z warstwą g-k } \\
\text { Polyurethane board } \\
\text { with plasterboard }\end{array}$} & \multirow{2}{*}{38} & koszt ogrzewania - heating cost & 3579 & 2428 & 2032 & 2032 & 1888 \\
\hline & & koszt izolacji - insulation cost & 13746 & 19664 & 29148 & 29148 & 30210 \\
\hline & \multirow{2}{*}{77} & koszt ogrzewania - heating cost & 4595 & 2405 & 2022 & 2022 & 1828 \\
\hline & & koszt izolacji - insulation cost & 0 & 19664 & 26094 & 26094 & 30210 \\
\hline
\end{tabular}

Objaśnienie: WT - wymogi według Rozporządzenia (Dz.U. 2013 poz. 926) wraz z rokiem obowiązywania. Explanation: WT - requirements form Regulation (Dz.U. 2013 poz. 926) with year of validity. 
Pomiędzy kolejnymi etapami zaostrzania przepisów WT 2014 - WT 2021 brak jest istotnej różnicy w kosztach ogrzewania. Różnica pomiędzy kosztami ogrzewania omawianej kondygnacji budynku pomiędzy WT 2014

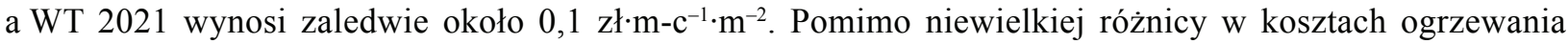
(WT 2014 - WT 2021) koszt wykonania izolacji wzrasta znacząco.

Zaostrzanie przepisów wpływa korzystnie na NPV inwestycji w okresie piętnastoletnim jedynie w przypadku zastosowania izolacji z płyt poliuretanowych dla muru $77 \mathrm{~cm}$ oraz izolacji z wełny mineralnej (tab. 4). W pozostałych przypadkach najkorzystniejszy jest wariant ograniczający ryzyko grzybów pleśniowych lub wariant WT 2013, który dopuszczał zwiększenie minimalnej wartości współczynnika $U$ dla budynków modernizowanych.

Tabela 4. Ocena inwestycji [PLN] w okresie piętnastoletnim przy zastosowaniu metody NPV (opracowanie własne)

Table 4. Investments evaluation $[\mathrm{PLN}]$ in period of fifteen years, using NPV method (own work)

\begin{tabular}{|c|c|c|c|c|c|c|}
\hline $\begin{array}{l}\text { Materiał } \\
\text { Material }\end{array}$ & $\begin{array}{c}\text { Grubość muru } \\
\text { Masonry thickness } \\
{[\mathrm{cm}]}\end{array}$ & $\begin{array}{l}\text { Wariant minimalny } \\
\text { Basic insulation }\end{array}$ & WT 2013 & WT 2014 & WT 2017 & WT 2021 \\
\hline \multirow{2}{*}{$\begin{array}{l}\text { Mineralne płyty izolacyjne } \\
\text { Mineral insulation boards }\end{array}$} & 38 & 58024 & 65798 & 64324 & 64324 & 61235 \\
\hline & 77 & - & 16331 & 14686 & 14686 & 11544 \\
\hline $\begin{array}{l}\text { Wełna mineralna na ruszcie } \\
\text { drewnianym }\end{array}$ & 38 & 66403 & 79176 & 83921 & 85359 & 85993 \\
\hline $\begin{array}{l}\text { Mineral wool on wooden } \\
\text { frame }\end{array}$ & 77 & - & 27701 & 33188 & 33188 & 34165 \\
\hline $\begin{array}{l}\text { Płyty poliuretanowe } \\
\text { z warstwą g-k }\end{array}$ & 38 & 56466 & 70540 & 67934 & 67934 & 69373 \\
\hline $\begin{array}{l}\text { Polyurethane board with } \\
\text { plasterboard }\end{array}$ & 77 & - & 18367 & 18596 & 18596 & 17840 \\
\hline
\end{tabular}

Objaśnienie: WT - wymogi według Rozporządzenia (Dz.U. 2013 poz. 926) wraz z rokiem obowiązywania.

Explanation: WT - requirements form Regulation (Dz.U. 2013 poz. 926) with year of validity.

Ocieplenie od wewnątrz wpływa na zmniejszenie powierzchni użytkowej. W przypadku budynku adaptowanego na cele biurowe z zamiarem późniejszego najmu powierzchni utracona powierzchnia wpływa bezpośrednio na rentowność przedsięwzięcia termomodernizacji. $Z$ tego względu w dalszej części analizy uwzględniono jej koszt. Ceny za wynajem powierzchni biurowej w centrum Warszawy wahają się od 12 do $25 € \cdot \mathrm{m}^{-2}$. Do dalszej analizy przyjęto miesięczny zysk z wynajmu nieruchomości wynoszący $70 \mathrm{zł} \cdot \mathrm{m}^{-2}$. Łączna długość ścian podlegających ociepleniu w przedmiotowej kondygnacji budynku wynosi 51,56 m. Łączny koszt utraty powierzchni użytkowej dla jednej kondygnacji zaprezentowano w tabeli 5.

W większości przypadków koszty utraty powierzchni użytkowej przewyższają oszczędności na ogrzewaniu (tab. 5). Bez uwzględniania wzrostu kosztów energii cieplnej oraz utraty wartości pieniądza w czasie najkorzystniejszy wariant ocieplenia wykonanego według WT 2014 zwróciłby się po 237 miesiącach.

Ocena opłacalności inwestycji, uwzględniająca utraconą powierzchnię użytkową, pokazuje, że w okresie piętnastoletnim $\mathrm{w}$ większości przypadków inwestycja $\mathrm{w}$ termomodernizację od wewnątrz nie jest opłacalna (tab. 6). Straty znacznie powiększają się w kolejnych etapach zaostrzania przepisów. Najrozsądniejszym z wariantów w każdym przypadku analizowanych technologii jest minimalna grubość izolacji, która wymagana jest do zapewnienia właściwych warunków higieniczno-zdrowotnych (tab. 6). Dzięki niskiemu 
Rogala, W. (2017). Warunki techniczne w odniesieniu do termomodernizacji obiektów zabytkowych. Acta Sci. Pol. Architectura, 16 (2), 77-84. doi: 10.22630/ASPA.2017.16.2.10.

Tabela 5. Roczny koszt utraty powierzchni użytkowej [PLN] (opracowanie własne)

Table 5. The annual cost of the loss of usable area $[\mathrm{PLN}]$ (own work)

\begin{tabular}{|c|c|c|c|c|c|c|}
\hline $\begin{array}{l}\text { Materiał } \\
\text { Material }\end{array}$ & $\begin{array}{c}\text { Grubość muru }[\mathrm{cm}] \\
\text { Masonry thickness } \\
{[\mathrm{cm}]}\end{array}$ & $\begin{array}{l}\text { Wariant minimalny } \\
\text { Basic insulation }\end{array}$ & WT 2013 & WT 2014 & WT 2017 & WT 2021 \\
\hline \multirow{2}{*}{$\begin{array}{l}\text { Mineralne płyty izolacyjne } \\
\text { Mineral insulation boards }\end{array}$} & 38 & 2469 & 4634 & 7233 & 8099 & 8965 \\
\hline & 77 & - & 3768 & 6367 & 6367 & 8099 \\
\hline $\begin{array}{l}\text { Wełna mineralna na ruszcie } \\
\text { drewnianym }\end{array}$ & 38 & 2729 & 4894 & 7060 & 7926 & 9225 \\
\hline $\begin{array}{l}\text { Mineral wool on wooden } \\
\text { frame }\end{array}$ & 77 & - & 4028 & 7060 & 7060 & 8359 \\
\hline $\begin{array}{l}\text { Płyty poliuretanowe } \\
\text { z warstwą g-k }\end{array}$ & 38 & 1516 & 2815 & 4114 & 4114 & 4981 \\
\hline $\begin{array}{l}\text { Polyurethane board with } \\
\text { plasterboard }\end{array}$ & 77 & - & 2382 & 3681 & 3681 & 4981 \\
\hline
\end{tabular}

Objaśnienie: WT - wymogi według Rozporządzenia (Dz.U. 2013 poz. 926) wraz z rokiem obowiązywania.

Explanation: WT - requirements form Regulation (Dz.U. 2013 poz. 926) with year of validity.

Tabela 6. Ocena inwestycji [PLN] w okresie piętnastoletnim z uwzględnieniem utraconej powierzchni użytkowej przy zastosowaniu metody NPV (opracowanie własne)

Table 6. Investments evaluation [PLN] in period of fifteen years, using NPV method including the loss of usable area (own work)

\begin{tabular}{|c|c|c|c|c|c|c|}
\hline $\begin{array}{l}\text { Materiał } \\
\text { Material }\end{array}$ & $\begin{array}{c}\text { Grubość muru }[\mathrm{cm}] \\
\text { Masonry thickness } \\
{[\mathrm{cm}]}\end{array}$ & $\begin{array}{l}\text { Wariant minimalny } \\
\text { Basic insulation }\end{array}$ & WT 2013 & WT 2014 & WT 2017 & WT 2021 \\
\hline \multirow{2}{*}{$\begin{array}{l}\text { Mineralne płyty izolacyjne } \\
\text { Mineral insulation boards }\end{array}$} & 38 & 21541 & -2687 & -42565 & -55366 & -71257 \\
\hline & 77 & - & -52155 & -92203 & -105004 & -120947 \\
\hline $\begin{array}{l}\text { Wełna mineralna na ruszcie } \\
\text { drewnianym }\end{array}$ & 38 & 26080 & 6850 & -20408 & -31771 & -50339 \\
\hline $\begin{array}{l}\text { Mineral wool on wooden } \\
\text { frame }\end{array}$ & 77 & - & -44626 & -71141 & -83943 & -102167 \\
\hline $\begin{array}{l}\text { Płyty poliuretanowe } \\
\mathrm{z} \text { warstwą g-k }\end{array}$ & 38 & 34064 & 28936 & 7129 & 7129 & -4233 \\
\hline $\begin{array}{l}\text { Polyurethane board with } \\
\text { plasterboard }\end{array}$ & 77 & - & -23236 & -42209 & -42209 & -55766 \\
\hline
\end{tabular}

Objaśnienie: WT - wymogi według Rozporządzenia (Dz.U. 2013 poz. 926) wraz z rokiem obowiązywania.

Explanation: WT - requirements form Regulation (Dz.U. 2013 poz. 926) with year of validity.

współczynnikowi przewodzenia ciepła najkorzystniej wypadają płyt poliuretanowe z warstwą g-k. Należy jednak pamiętać, że jest to materiał o klasie reakcji na ogień B2, a poprawne funkcjonowanie jest możliwe jedynie przy zapewnieniu szczelnych połączeń pomiędzy płytami. Z tego względu materiał nie cieszy się dużą popularnością. 


\section{PODSUMOWANIE I WNIOSKI}

Stosownie do Raportu o stanie zabytków nieruchomych (Departament Ochrony Zabytków Ministerstwa Kultury, 2004) w 2003 roku Polsce znajdowało się 45240 obiektów kubaturowych wpisanych do rejestru zabytków. Co więcej, istnieje duża grupa obiektów, które pomimo braku wpisu do Rejestru zabytków cechuje duża wartość architektoniczna lub historyczna elewacji. Jedynym sposobem na ocalenie sensu funkcjonowania tych obiektów i tym samym zachowanie dziedzictwa kulturowego jest ocieplenie ich od wewnątrz.

Wyniki przeprowadzonej analizy wskazują, że kolejne etapy zaostrzania przepisów dotyczących zużycia energii cieplnej nie przynoszą wymiernych korzyści przy ociepleniu obiektów od wewnątrz. W praktyce nieracjonalne wymogi termiczne dla obiektów modernizowanych mogą powodować kilka zagrożeń:

1. Z uwagi na nieracjonalny koszt termomodernizacji obiekty te nie zostaną ocieplone. Będą funkcjonowały jako obiekty z innym przeznaczeniem, które będzie w stanie sprostać znacznie wyższym kosztom eksploatacji. Taki wariant nie spowoduje ograniczenia emisji $\mathrm{CO}_{2}$, a problem smogu w dużych aglomeracjach nie zostanie rozwiązany.

2. Obiekty zostaną ocieplone, ale jedynie do wariantu ekonomicznie uzasadnionego. Taki wariant spowoduje zachowanie sensu funkcjonowania tych obiektów, ale będzie wykonany z pominięciem obowiązujących przepisów.

3. Obiekty zostaną ocieplone od zewnątrz. Obiekty te zachowają sens funkcjonowania, emisja gazów cieplarnianych zostanie ograniczona, ale zniszczona zostanie ich wartość historyczna i architektoniczna.

Zdaniem autora, przy opracowywaniu nowelizacji Rozporządzenia z dnia 13 lipca 2013 r. (Dz. U. 2002 nr 75 poz. 926) nie objęto analizą obiektów istniejących, które powinny zostać ocieplone od wewnątrz. Ocieplanie obiektów istniejących stanowi dobrowolny akt inwestora podyktowany względami ekonomicznymi, na którym zyskuje społeczeństwo i środowisko. Dzięki ocieplaniu obiektów istniejących zostaje zmniejszona emisja $\mathrm{CO}_{2}$ oraz ograniczone zużycie surowców nieodnawialnych. Jeśli obiekty istniejące zostałyby wyłączone z konieczności spełnienia granicznych wartości współczynników przenikania ciepła, to mogłyby zostać ocieplone do wariantu ekonomicznie uzasadnionego. Oszczędności na kosztach ocieplenia mogłyby zostać zainwestowane w modernizację wentylacji, a to przełożyłoby się na korzystniejszy efekt termomodernizacji (Jarosz-Hadam i Fic, 2016).

\section{PIŚMIENNICTWO}

Bioenergia dla regionu - Badanie zarządzania zmianą gospodarczą, Prognoza wzrostu cen energii elektrycznej i ciepła dla gospodarstw domowych i przedsiębiorstw w województwie mazowieckim (2012). Pobrano z lokalizacji: www.efs.20072013.gov.pl (dostęp: 15.01.2017).

Harassek, P. i Bajno, D. (2016). Multipor. Ocieplanie od wewnatrz. Warszawa: Xella Polska.

Jarosz-Hadam, M. i Fic, P. (2016). Ocena zmniejszenia strat energii cieplnej budynku wielorodzinnego w wyniku przeprowadzonej termomodernizacji. Budownictwo i Architektura, 15(4), 101-108.

Ostańska, A. i Barnat-Hunek, D. (2014). Ocena efektywności dociepleń od strony wewnętrznej na przykładzie zabytkowego obiektu szpitalnego w Tworkach. Wiadomości Konserwatorskie, 37, 22-34.

PN-EN ISO 6946:1999. Komponenty budowlane i elementy budynku. Opór cieplny i współczynnik przenikania ciepła. Metoda obliczania

PN-EN ISO 6946:2008. Komponenty budowlane i elementy budynku. Opór cieplny i współczynnik przenikania ciepła. Metoda obliczania

PN-EN ISO 13789:2008. Cieplne właściwości użytkowe budynków. Współczynniki przenoszenia ciepła przez przenikanie i wentylację. Metoda obliczania.

PN-EN ISO 13790:2009. Energetyczne właściwości użytkowe budynków. Obliczanie zużycia energii na potrzeby ogrzewania i chłodzenia. 
Raport sporządzony na zlecenie Ministerstwa Kultury (2004). Raport o stanie zabytków nieruchomych. Pobrano z lokalizacji: http://www.nid.pl/pl/Informacje_ogolne/Zabytki_w_Polsce/rejestr-zabytkow/zestawienia-zabytkow-nieruchomych/ Raport_o_stanie_zabytkow_2004.pdf.

Rozporządzenie Ministra Infrastruktury z dnia 12 kwietnia 2002 r. w sprawie warunków technicznych, jakim powinny odpowiadać budynki i ich usytuowanie (Dz.U. $2002 \mathrm{nr} 75$ poz. 690).

Rozporządzenie Ministra Infrastruktury z dnia 6 listopada 2008 r. zmieniające rozporządzenie w sprawie warunków technicznych, jakim powinny odpowiadać budynki i ich usytuowanie (Dz.U. 2008 nr 201 poz. 1238).

Rozporządzenie Ministra Transportu, Budownictwa i Gospodarki Morskiej z dnia 5 lipca 2013 r. zmieniające rozporządzenie w sprawie warunków technicznych, jakim powinny odpowiadać budynki i ich usytuowanie (Dz.U. 2013 poz. 926).

Ustawa z dnia 7 lipca 1994 r. - Prawo budowlane (Dz.U.2016 poz. 290).

\section{REGULATION ON TECHNICAL CONDITIONS IN REFERENCE TO HISTORICAL BUILDINGS}

\section{ABSTRACT}

An essay raises the issue of thermal modernization of historical buildings in relation to tightening the regulations on energy consumption. Two storeys of multi-family housing adapted for office purposes were examined. Calculation were made for three variants of thermal insulation from the inside - mineral wool on wood frame, mineral insulation boards and polyurethane boards with plasterboard. All variants cover heat transfer coefficient requirements defined in regulations for the years 2013, 2014, 2017 and 2021. The analysis was based on the NPV method and is supplemented by the cost of the loss of usable space. An analysis of the 15 -year period indicates, that thermo-modernization from the inside in the examine housings would not be cost-efficient after tightening the thermal regulations in 2014, 2017 and 2021.

Key words: insulation from the inside, thermo-modernization of historical buildings, requirements for historical buildings, energy performance of historical buildings 